\title{
Developing the Korean Association of Medical Colleges graduate outcomes of basic medical education based on "the role of Korean doctor, 2014"
}

Min Jeong Kim', Young-Mee Lee ${ }^{2}$, Jae Jin Han ${ }^{3}$, Seok Jin Choi ${ }^{4}$, Tae-Yoon Hwang ${ }^{5}$, Min Jeong Kwon ${ }^{6}$, Hyouk-Soo Kwon ${ }^{7}$, Man-Sup Lim ${ }^{8}$, Won Min Hwang ${ }^{9}$, Min Cheol Joo ${ }^{10}$, Jong-Tae Lee ${ }^{111^{*}}$ and Eunbae B. Yang ${ }^{12 *}$

${ }^{1}$ Department of Medical Education and Neurology, Kosin University College of Medicine, Busan, ${ }^{2}$ Department of Medical Education, Korea University College of Medicine, ${ }^{3}$ Department of Medical Education, Ewha Womans University School of Medicine, Seoul, ${ }^{4}$ Department of Radiology, Inje University College of Medicine, Busan, ${ }^{5}$ Department of Preventive Medicine \& Public Health, Yeungnam University College of Medicine, Daegu, ${ }^{6}$ Department of Internal Medicine, Inje University College of Medicine, Busan, ${ }^{7}$ Department of Allergy and Clinical Immunology, University of Ulsan College of Medicine, Seoul, ${ }^{8}$ Department of Medical Education, Hallym University College of Medicine, Chuncheon, ${ }^{9}$ Department of Internal Medicine, Konyang University College of Medicine, Daejeon, ${ }^{10}$ Department of Rehabilitation Medicine, Wonkwang University School of Medicine, Iksan, ${ }^{11}$ Department of Preventive Medicine, Inje University College of Medicine, Busan, and ${ }^{12}$ Department of Medical Education, Yonsei University College of Medicine, Seoul, Korea

The Korean Association of Medical Colleges (KAMC) developed graduate outcomes based on "The role of Korean doctor, 2014" to serve as guidelines regarding outcome-based education in Korea. The working group in this study analyzed 65 competencies proposed in "The role of Korean doctor, 2014" according to the developmental principle that certain outcomes should be demonstrated at the point of entry into the graduate medical education. We established 34 competencies as "preliminary graduate outcomes" (PGOs). The advisory committee consisted of 11 professors, who reviewed the validity of PGOs. Ultimately, a total of 19 "revised graduate outcomes" (RGOs) were selected. We modified the RGOs based on opinions from medical schools and a public hearing. In November 2017, the KAMC announced the "graduate outcomes for basic medical education," which serves as a guide for basic medical education for the 40 medical schools throughout Korea. Medical schools can expand the graduate outcomes according to their educational goals and modify them according to their own context. We believe that graduate outcomes can be a starting point for connecting basic medical education to graduate medical education.

Key Words: Competency-based education, Physician's role, Undergraduate medical education, Republic of Korea

\section{Introduction}

The purpose of medical education is to equip physicians with competencies that will satisfy the reasonable expectations of patients and society. Recently, emphasis has been placed on outcome-based medical education (OBME), or competency-based medical education, which defines outcomes that students must achieve, the faculty designated to teach the material, how it must be taught,
Received: April 20, 2018 • Revised: May 8, 2018 • Accepted: May 8, 2018

Corresponding Author: Eunbae B. Yang (https://orcid.org/0000-0002-6771-1929)

Department of Medical Education, Yonsei University College of Medicine, 50-1 Yonsei-ro, Seodaemun-gu, Seoul 03722, Korea

Tel: +82-2-2228-2511 Fax: +82-2-364-5450 email: nara@yuhs.ac Corresponding Author: Jong-Tae Lee (https://0000-0002-6132-897X)

Department of Preventive Medicine, Inje University College of Medicine, 75 Bokji-ro, Busanjin-gu, Busan 47392, Korea

Tel: +82.51.890.6300 Fax:+82.51.895.1864 email: pmljt742@inje.ac.kr

*These two authors contributed equally to this work.
Korean J Med Educ 2018 Jun; 30(2): 79-89.

https://doi.org/10.3946/kjme.2018.83

eISSN: 2005-7288

(C) The Korean Society of Medical Education. All rights reserved. This is an open-access article distributed under the terms of the Creative Commons Attribution Non-Commercial License (http:// creativecommons.org/licenses/by-nc/3.0/), which permits unrestricted non-commercial use, distribution, and reproduction in any medium, provided the original work is properly cited. 
and how to evaluate what has been taught [1]. In fact, OBME has quickly spread throughout the United States and Canada, as well as England and other European countries, since 1980, and it has provided medical schools with an impetus to improve their educational methodology [2]. The General Medical Council in the United Kingdom provides guidance to medical practitioners through its standard entitled "Good Medical Practice," which describes what it means to be a good doctor and defines outcomes that medical students must be able to demonstrate in order to graduate $[3,4]$. The Accreditation Council for Graduate Medical Education (ACGME) and the American Board of Medical Specialties in the United States proposed six core competencies that residents should achieve during their medical training [5]. The Association of American Medical Colleges developed the core Entrustable Professional Activities (EPAs) for Entering Residency in 2014 [6]. Canada also analyzed the competencies that doctors must acquire to meet the needs of society, and conceived the Canadian Medical Education Directions for Specialists framework (CanMEDS framework; 2005, 2015). The CanMEDS framework is being used in many other countries as a foundation for OBME curriculum development [7].

In Asia, the National Medical Undergraduate Curriculum Committee in Singapore presented the "Outcomes and standards for undergraduate medical education in Singapore" in 2014. The report contains long-term directions for the healthcare workforce, as well as outcomes and standards for medical education [8]. China also recognized that its medical education system needed to be improved innovatively to keep up with the rapid changes in the healthcare environment. Zhao et al. [9] conducted a large-scale survey to identify the role of Chinese physicians in the Chinese healthcare environment; their findings led to elucidation of a framework based on six competencies. Lio et al. [10] also proposed competencies for residency training programs.

In 2012, the Korean Institute for Medical Education and Evaluation introduced "Post-2nd cycle accreditation standards" for basic medical education in South Korea; these standards emphasize OBME. The announcement about the accreditation standards led to discussions on the development and implementation of OBME curricula [11]. Research on the roles of Korean doctors began in the early 2000s [12-14]. Many studies have reported on the roles of future physicians, but there has been a lack of research on the competencies that future doctors must demonstrate. There has also not been any agreement on a competency framework at the national level. Therefore, medical schools have begun defining competencies that their graduates should achieve during basic medical training. It should be noted that OBME in Korea is approached differently than it is in the United States, England, Canada, and other countries. Ahn et al. [15] conducted a study on the future roles of Korean doctors with funding from the Ministry of Health and Welfare. He and his colleagues proposed five domains (patient care, professionalism, social accountability, communication and collaboration, and education and research) and 65 competencies for Korean doctors. In 2014, the Council for Medical Education in Korea the consultative committee of 13 organizations related to medical education (the Korean Academy of Medical Sciences, the Korean Society of Medical Education, the Korean Medical Association, the Korean Institute of Medical Education and Evaluation, the Korean Association of Medical Colleges [KAMC], the Korean Hospital Association, the Korean Medical Practitioners Association, the Korean Association of Basic Medical Scientists, the Medical Professors Association of Korea, the National Teacher Training Center for Health Personnel, etc.)-ratified that Korean doctors should have 65 competencies in five domains, in "The role of Korean doctor, 2014" (Appendix 1). 
"The role of Korean doctor, 2014" is a proclamatory description of a doctor's virtues and roles that professional community and our societies have agreed to and accepted $[15,16]$. There are difficulties in applying this standard to the basic medical education phase. Yang et al. [17] analyzed the applicability of 65 competencies stipulated by "The role of Korean doctor, 2014" to the curricula of various medical schools. They also proposed the need for the development of graduate outcomes of basic medical education to be used by medical schools based on "The role of Korean doctor, 2014" and reported that 38 of 40 medical schools insisted on being provided with the curriculum developer's guidelines for OBME. Ultimately, the KAMC developed the "Graduate outcomes for basic medical education" to provide medical colleges a guidance which can implement OBME in Korea.

\section{Development of graduate outcomes for basic medical education}

\section{Process and principles for graduate out- comes development}

The Education Committee of the KAMC formed a working group to develop graduate outcomes of basic medical education based on "The role of Korean doctor, 2014." Members of the working group for the project on graduate outcomes development (WGGOD) were selected based on their majors. Professors who took part in developing "The role of Korean doctor, 2014" and experts who were experienced in developing OBME curricula participated in the group. We did not include other stakeholders in the working group because a lot of stakeholders, such as students, citizens, general practitioners, and other organizations, were included in the process of developing "The role of Korean doctor, 2014."
The WGGOD was active between April 2016 and November 2017 in developing graduate outcomes of basic medical education. To establish a common foundation for members in development of the outcomes, the WGGOD studied changes in the healthcare environment, issues related to OBME development, and cases of the ACGME competency framework of the United States, CanMEDS 2015 physician competency framework of Canada, and the learning outcomes framework for Scottish doctors. As Harden [18] mentioned, we found that the level of outcome emphasize a broad overview with a design-down approach to a more detailed competency. Also in terms of classification and interrelationship of outcomes, it is structured in the form of learning outcomes with nesting of outcomes, knowledge embedded and meta-competences recognized. The WGGOD also reviewed the appropriateness of the 65 competencies stipulated in "The role of Korean doctor, 2014" as graduate outcomes of basic medical education. The review process involved group discussions and consensus. The definition, level and classification of defined in "The role of Korean doctor, 2014" were not much different from foreign outcome framework. Fig. 1 describes the WGGOD's process for developing the outcomes. The following are principles applied during the review process. First, the graduate outcomes of basic medical education were based on the 65 competencies stipulated in "The role of Korean doctor, 2014.” Second, graduate outcomes for basic medical education should be demonstrated upon entering a graduate medical education program. Third, graduate outcomes of basic medical education are common and core outcomes that can be used by all medical schools. Medical schools should be able to expand graduate outcomes according to their own educational goals and objectives. Fourth, graduate outcomes of basic medical education should have an association with the learning outcomes developed by the KAMC (e.g., the KAMC published in several books, guides to clinical performance, guides to basic clinical 
Fig. 1. Working Flows for Graduate Outcomes Development

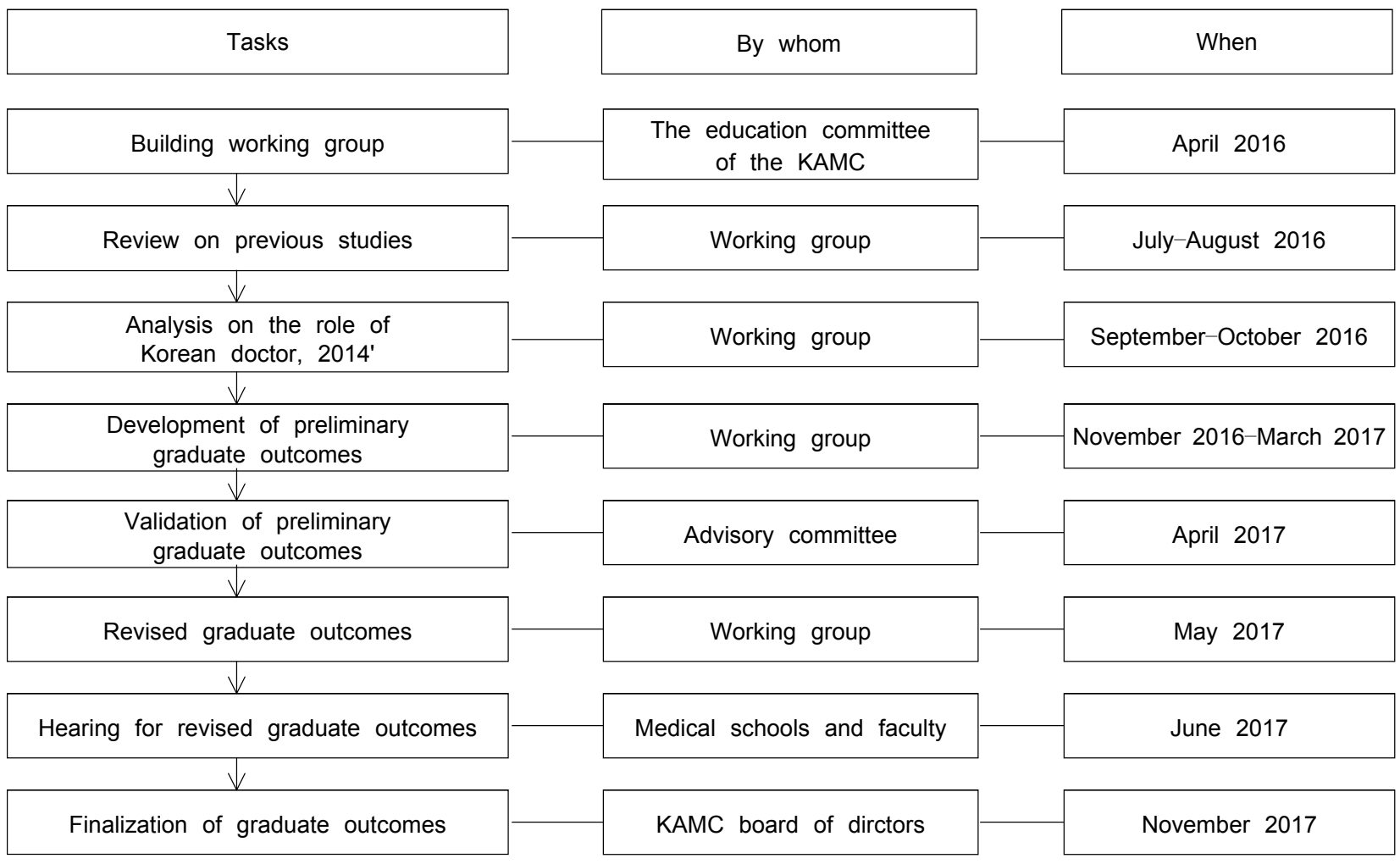

KAMC: Korean Association of Medical Colleges.

skills, learning outcomes of basic medical education: scientific concept- and principle-centered outcomes, learning outcomes of basic medical education: clinical competency-centered outcomes, and learning outcomes of basic medical education: human- and society-centered outcomes). Fifth, graduate outcomes of basic medical education include competencies required by doctors in the future. Sixth, they reflect the feasibility of education and assessment of competencies in medical schools.

\section{Development of preliminary graduate out- comes}

Each of the 65 competencies proposed in "The role of Korean doctor, 2014" was analyzed according to the developmental principles for the graduate outcomes of basic medical education mentioned previously. We classified the competencies as follows: (1) competencies that should be completed during the basic medical education phase (category I); (2) competencies that begin to develop during the basic medical education phase and should be attained during the graduate medical education phase (category II); and (3) competencies that begin to develop and which should be completed during the graduate medical education phase (category III). We excluded category III from the graduate outcomes for basic medical education, according to the principle that such outcomes should be achieved upon entering a graduate medical education program. Categories I and II were adjusted and integrated to fit the basic medical education phase. We identified 34 competencies as preliminary graduate outcomes (PGOs). Table 1 shows the division by domain for the PGOs.

\section{Validation of preliminary graduate out- comes by professionals}

The advisory committee for the WGGOD included 11 


\begin{tabular}{|c|c|c|c|}
\hline \multirow[b]{2}{*}{ Domain } & \multicolumn{2}{|c|}{ No. of competency } & \multirow[b]{2}{*}{ Deleted items ${ }^{\text {al }}$ in the role of Korean doctor, 2014} \\
\hline & $\begin{array}{c}\text { The role of } \\
\text { Korean doctor, } 2014\end{array}$ & $\begin{array}{l}\text { Preliminary graduate } \\
\text { outcomes }\end{array}$ & \\
\hline Patient care & 15 & 9 & $6,7,8,9,10,11,12,14$ \\
\hline Communication and collaboration & 17 & 5 & $18,19,20,21,23,26,27,28,29,30,31,32$ \\
\hline Social accountability & 11 & 5 & $35,42,43$ \\
\hline Professionalism & 15 & 8 & $44,45,47,53,54,56,57,58$ \\
\hline Education and research & 7 & - & 63 \\
\hline Self-improvement & - & 5 & \\
\hline Knowledge application & - & 2 & \\
\hline Sum & 65 & 34 & \\
\hline
\end{tabular}

${ }^{a}$ Of the 65 competencies in "The role of Korean doctor, 2014," category III items that begin at the postgraduate training stage and competencies that could be integrated with others were deleted. The competency corresponding to the number of deleted items can be found in Appendix 1 .

\begin{tabular}{|c|c|c|c|}
\hline Domain & The role of Korean doctor, 2014 & Preliminary graduate outcomes & Revised graduate outcomes \\
\hline Patient care & 15 & 9 & 8 \\
\hline Communication and collaboration & 17 & 5 & 3 \\
\hline Social accountability & 11 & 5 & 2 \\
\hline Professionalism & 15 & 8 & 3 \\
\hline Education and research & 7 & - & - \\
\hline Self-improvement & - & 5 & - \\
\hline Knowledge application & - & 2 & 3 \\
\hline Sum & 65 & 34 & 19 \\
\hline
\end{tabular}

professors from medical colleges who reviewed the validity of the PGOs. This committee consisted of medical educators from the fields of internal medicine, surgery, obstetrics and gynecology, pediatrics, psychiatry, and family medicine, and they have been in charge of medical education and residency training in their colleges. They were selected based on their expertise in the field of medical education and activities related to OBME. Regarding the 34 PGOs, we asked for the advisory committee's written opinion on the following: (1) the appropriateness of PGOs, (2) the validity of achievement levels, (3) exclusiveness in terms of other competencies, (4) clarity of the descriptions, and (5) feasibility of education and assessment. An offline discussion with the advisory committee was held on April 10, 2017, and the following conclusions were formulated. First, there were some overlaps among the 34 PGOs developed by the
WGGOD, indicating that they had to be reviewed and configured as mutually exclusive items. Second, to increase the feasibility of education and assessment at medical schools, the number of PGOs should be reduced. Third, because achievement of some PGOs could not be realized at the point when a student completes basic medical education, the achievement level of the PGOs should be adjusted for students entering a graduate medical education institution. The WGGOD revised the graduate outcomes of basic medical education based on the consensus of the advisory committee and developed 19 outcomes, as shown in Table 2.

\section{Hearing and finalization for revised graduate outcomes}

The WGGOD requested a review of the appropriateness of the revised graduate outcomes (RGOs) from 40 
medical schools to verify their acceptability for the basic medical education phase. In May 2017, we held a public hearing for faculty members who were recommended by medical schools. The following is a summary of the opinions of medical schools and the results of the public hearing. First, the RGOs of basic medical education that have been developed were appropriate and are very likely to be accepted by medical schools. Second, application of the RGOs should not be imposed on all medical schools. Additionally, medical schools should be able to expand or modify the RGOS according to their own educational goals and objectives. Third, it is important to develop assessment tools for evaluating the RGOs to increase the feasibility of their implementation in medical schools. Fourth, the context in which the
RGOs are situated needs to be addressed. The WGGOD developed the RGOs based on reviews by medical schools and opinions expressed during the public hearing. In November 2017, the 19 graduate outcomes of basic medical education were approved by the KAMC board of directors and officially announced. Table 3 shows the final graduate outcomes of basic medical education according to the five domains of patient care, application of knowledge, communication and collaboration, social accountability, and professionalism.

The final graduate outcomes for basic medical education were proposed by outcome name, context of performance (context in which the outcome is performed), achievement level (required achievement level at the basic medical education phase), and relevance (how it

Table 3. Final Graduate Outcomes of Basic Medical Education Developed by the Korean Association of Medical Colleges

\begin{tabular}{|c|c|}
\hline Domain & Graduate outcomes \\
\hline Patient care & $\begin{array}{l}\text { 1. The graduate is able to obtain the patient's medical history accurately in an effort to solve his/her problems. } \\
\text { 2. The graduate is able to perform a physical examination competently in a given medical interview situation. } \\
\text { 3. The graduate is able to perform basic clinical skills and procedures necessary for patient care. } \\
\text { 4. The graduate is able to choose diagnostic and screening tests required to solve the patient's problems and } \\
\text { interpret the results. } \\
\text { 5. The graduate is able to carry out reasonable diagnostic inferences based on patient information and scientific } \\
\text { evidence. } \\
\text { 6. The graduate is able to plan and manage patient-centered care based on the proper medical evidence. } \\
\text { 7. The graduate is able to maintain accurate medical records and make the best use of them. } \\
\text { 8. The graduate should recognize prevention and handling strategies for patient safety incidents and conduct } \\
\text { timely intervention. }\end{array}$ \\
\hline $\begin{array}{l}\text { Knowledge } \\
\text { application }\end{array}$ & $\begin{array}{l}\text { 9. The graduate is expected to acquire scientific knowledge and apply it to solve medical problems. } \\
\text { 10. The graduate is able to utilize the latest medical research and scientific methods needed to solve patients' } \\
\text { problems. } \\
\text { 11. The graduate should learn various research methodologies pertaining to medicine and design medical research } \\
\text { studies according to ethics and guidelines research. }\end{array}$ \\
\hline $\begin{array}{l}\text { Communication and } \\
\text { collaboration }\end{array}$ & $\begin{array}{l}\text { 12. The graduate is able to empathize with the patient's perspective and communicate effectively. } \\
\text { 13. The graduate can identify challenging situations, such as those requiring the delivery of bad news or difficulty } \\
\text { with communication, and is able to adopt effective strategies in such situations. } \\
\text { 14. The graduate is able to communicate and collaborate with colleagues participating in medical practices. }\end{array}$ \\
\hline Social accountability & $\begin{array}{l}\text { 15. The graduate can identify the health issues of the community or population and make plans for improvement. } \\
\text { 16. The graduate should understand the healthcare policy and should be able to suggest response strategies } \\
\text { according to the healthcare paradigm for the future. }\end{array}$ \\
\hline Professionalism & $\begin{array}{l}\text { 17. The graduate should understand the principles of bioethics and medical ethics and be able to apply them } \\
\text { in medical practice. } \\
\text { 18. The graduate should internalize honesty, sincerity, altruism, humility, respect for others, and empathy as } \\
\text { core values of his/her profession and should be able to demonstrate them in daily practices. } \\
\text { 19. The graduate should reflect his/her own competencies and develop the ability to be a lifelong learner. }\end{array}$ \\
\hline
\end{tabular}


Table 4. Sample Format for Presenting Graduate Outcomes

\begin{tabular}{|c|c|}
\hline Domain: patient care & Description \\
\hline Graduate outcome 1 & 1. The graduate is able to obtain a patient's medical history accurately to solve his/her problems. \\
\hline Context & $\begin{array}{l}\text { A process for collecting information and interacting with patients is the foundation for understanding the } \\
\text { patient and managing his/her care. The physician must be able to prioritize problems and obtain an accurate } \\
\text { medical history using a systematic approach. When obtaining patients' medical histories, doctors should } \\
\text { consider certain clinical situations and the individuation of patients to ensure a patient-centered approach. } \\
\text { Doctors should obtain appropriate medical histories according to general practice situations, emergency } \\
\text { situations, patient symptoms, acute or chronic disease, and so on. }\end{array}$ \\
\hline Achievement criterion & $\begin{array}{l}\text { Medical graduates are able to identify the priorities of the problem and obtain medical history accurately } \\
\text { and systematically according to a patient-centered approach. }\end{array}$ \\
\hline $\begin{array}{l}\text { Relation to future role of } \\
\text { the Korean doctor }\end{array}$ & $\begin{array}{l}\text { 1. Doctors shall possess professional medical knowledge and appropriate clinical skills. } \\
\text { 2. Doctors shall maintain a patient-centered approach when assessing, diagnosing,and treating patients and } \\
\text { be capable of delivering accurate medical judgments and appropriate clinical decisions. } \\
\text { 3. Patient care shall be based on scientific evidence and the individual nature of each patient. }\end{array}$ \\
\hline
\end{tabular}

relates to "The role of Korean doctor, 2014"). Table 4 shows the final graduate outcomes of basic medical education and a sample format.

\section{Discussion}

The development of graduate outcomes of basic medical education started with the need to establish core competencies to be cultivated by medical schools based on "The role of Korean doctor, 2014." The KAMC developed the "Graduate outcomes for basic medical education" as a guide for basic medical education for the 40 medical schools throughout Korea. Notwithstanding, there are still several issues that we should consider in relation to developing and applying these outcomes.

First, there are differences in the number of outcomes that are included in five domains. There is the possibility of misunderstanding the importance of each outcome because of these differences. The time durations required for teaching and learning each outcome are also different. Additionally, some outcomes can be acquired within a certain period, but others require continuous attention throughout the basic medical education curriculum. It is, therefore, not appropriate to consider all outcomes as equal. The second issue relates to the achievement levels of graduate outcomes of basic medical education. To elaborate, there are debates on whether the specified outcome to be achieved should describe the ultimate achievement level expected of doctors, or if it should describe the achievement level that medical students are expected to demonstrate at the point of entry into the graduate medical education program. It is best to describe the achievement level of medical students after specifying the ultimate achievement level expected of doctors upon completing the medical education continuum. Regarding the achievement of graduate outcomes, it is important that stakeholders agree on the transition between basic medical education and graduate medical education. In this project, such agreements were not made; therefore, we have defined the achievement level expected of medical students at the point of entry into the graduate medical education program. The purpose of developing graduate outcomes of basic medical education is to reinforce OBME in medical schools. We hope that follow-up research will address these issues.

The third issue is how to measure and assess whether medical students are achieving the graduate outcomes of basic medical education. The key to the success of 
OBME is developing valid and reliable assessment tools to verify the achievements of students. The assessment will not only be a criterion for determining whether individual students have achieved the outcomes, but will also drive learning and provide information on the effectiveness of medical education [19-21]. Many medical schools have petitioned that it is difficult to develop valid assessment tools [17]. In addition, medical schools must determine how to assess not only visible outcomes but also invisible outcomes when designing OBME curricula [19]. For further study, we are left with the task of developing assessment tools and studying examples to measure students' achievements of the graduate outcomes of basic medical education.

The "Graduate outcomes for basic medical education" is a set of guidelines for curriculum development in medical schools. However, the intention is not to imply that the outcomes must be adopted and implemented as graduate outcomes for all medical schools. Medical schools can expand the graduate outcomes according to their educational goals and modify them according to their own context. The competencies presented in "The role of Korean doctor, 2014" are expectations regarding the roles of doctors in our society. The graduate outcomes developed by the KAMC are core outcomes that medical students should achieve at the point of entry into the graduate medical education. We know that it is important to have a continuum from graduate outcomes of basic medical education to outcomes in residency training phase. Now the Korean Academy of Medical Sciences, which is in charge of the residency training, is working on the transformation of residency training into competency-based medical education based on "The role of Korean doctor, 2014." However, we were not able to carry out these tasks at the same time because it needed more time for consensus and coordination. We believe that graduate outcomes of basic medical educa- tion can be a starting point for linking outcomes of residency training program. In this context, the KAMC is working on a project to develop EPAs for entering intern and residency program to ensure a successful transition from the basic medical education phase to the graduate medical education phase in Korea.

\section{ORCID:}

Min Jeong Kim: https://orcid.org/0000-0002-1340-1060; Young-Mee Lee: https://orcid.org/0000-0002-4685-9465; Jae Jin Han: https://orcid.org/0000-0002-6499-7642; Seok Jin Choi: https://orcid.org/0000-0002-2688-4006; Tae-Yoon Hwang: https://orcid.org/0000-0001-9397-5314; Min Jeong Kwon: https://orcid.org/0000-0002-9616-870X; Hyouk-Soo Kwon: https://orcid.org/0000-0001-7695-997X; Man-Sup Lim: https://orcid.org/0000-0001-9222-2740; Won Min Hwang: https://orcid.org/0000-0001-7548-6111; Min Cheol Joo: https://orcid.org/0000-0003-2778-4194; Jong-Tae Lee: https://orcid.org/0000-0002-6132-897X; Eunbae B. Yang: https://orcid.org/0000-0002-6771-1929 Acknowledgements: None.

Funding: This work was supported by the Korean Association of Medical Colleges.

Conflicts of interest: No potential conflict of interest relevant to this article was reported.

Author contributions: Conception or design of the work: EBY, JTL, JJH; data collection: JJH, EBY, MCJ, HSK, TYH; data analysis and interpretation: MJK, YME, JJH, SJC, TYH, MJK, HSK, MSL, WMH, MCJ. EBY, JTL; drafting the article: MJK, EBY; critical revision of the article: MJK, YML, EBY, JTL; and final approval of the version to be published: MJK, YME, JJH, SJC, TYH, MJK, HSK, MSL, WMH, MCJ. EBY, JTL. 


\section{References}

1. Gruppen LD. Outcome-based medical education: implications, opportunities, and challenges. Korean J Med Educ. 2012;24(4):281-285.

2. Han JJ. The development of outcome-based curriculum in medical schools outside Korea. Korean Med Educ Rev. 2013;15(1):19-24.

3. General Medical Council. Good medical practice. https:// www.gmc-uk.org/static/documents/content/Good_medical _practice_-_English_1215.pdf. Published March 2013. Accessed December 20, 2017.

4. General Medical Council. Outcomes for graduates. https://www.gmc-uk.org/-/media/documents/Outcomes_ for_graduates_Jul_15_1216.pdf_61408029.pdf. Published July 2015. Accessed December 20, 2017.

5. Swing SR. The ACGME outcome project: retrospective and prospective. Med Teach. 2007;29(7):648-654.

6. Association of American Medical Colleges. Core entrustable professional activities for entering residency: curriculum developers' guide. https://members.aamc.org/ eweb/upload/Core\%20EPA\%20Curriculum\%20Dev\% 20Guide.pdf. Published May 2014. Accessed December $20,2017$.

7. Royal College of Physicians and Surgeons of Canada. CanMEDS 2015 framework. http://canmeds.royalcollege. ca/uploads/en/framework/CanMEDS\%202015\%20Frame work_EN_Reduced.pdf. Published October 2015. Accessed December 20, 2017.

8. Ministry of Health. Outcomes and standards for undergraduate medical education in Singapore. https://www. moh.gov.sg/content/dam/moh_web/HPP/Main/all_professi ons_cpgs/NMUCC_Report_singlepage.pdf. Published 2014. Accessed December 20, 2017.

9. Zhao L, Sun T, Sun BZ, Zhao YH, Norcini J, Chen L. Identifying the competencies of doctors in China. BMC Med Educ. 2015;15:207.
10. Lio J, Ye Y, Reddy S, Dong H, Sherer R. Developing a competency framework for medical education in China: a qualitative study. Med Sci Educ. 2016;26(4):743-748.

11. Korean Institute of Medical Education and Evaluation. Standards for the appraisal of medical education. http://www.kimee.or.kr/medical-education/criteria/. Accessed December 20, 2017.

12. Meng KH. Medical education plan for the twenty-first century in Korea: hopes and challenges. Korean J Med Educ. 2004;16(1):1-11.

13. Im JG, Shin JS. Physicians for 'here and now'. J Korean Med Assoc. 2012;55(2):110-112.

14. Lee MS, Cho SH, Park CI, Kim S. A study on improvement of the educational system for development and efficient management of health manpower. Sejong, Korea: Ministry of Health and Welfare; 2000.

15. Ahn DS, Han JJ, Lee MJ, et al. A study of the future roles of Korean doctors and current state of continuing medical education. Sejong, Korea: Ministry of Health and Welfare; 2013.

16. Ahn D. The future roles of Korean doctors: cultivating well-rounded doctors. Korean Med Educ Rev. 2014; 16(3):119-125.

17. Yang EB, Seo DJ, Han JJ. A study on curriculum development and evaluation based on the doctor's role in Korea. Seoul, Korea: Korean Medical Association; 2015.

18. Harden RM. Learning outcomes and instructional objectives: is there a difference? Med Teach. 2002;24(2): 151-155.

19. Holmboe ES, Sherbino J, Long DM, Swing SR, Frank JR. The role of assessment in competency-based medical education. Med Teach. 2010;32(8):676-682.

20. Lockyer J, Carraccio C, Chan MK, et al. Core principles of assessment in competency-based medical education. Med Teach. 2017;39(6):609-616.

21. Harris P, Bhanji F, Topps M, et al. Evolving concepts of assessment in a competency-based world. Med Teach. 2017;39(6):603-608. 


\section{Appendix 1. The Role of the Korean Doctor, 2014}

\section{[Domain 1: patient care]}

1. Doctors shall possess professional medical knowledge and appropriate clinical skills.

2. Doctors shall maintain a patient-centered approach when assessing, diagnosing, and treating the patient, and shall be capable of delivering accurate medical judgments and appropriate clinical decisions.

3. Patient care shall be based on scientific evidence and reflect consideration for the individual nature of each patient.

4. Decisions related to patient care shall be reached while respecting the patient's opinions through activities such as information provision, education, counseling, and collection of informed consent.

5. The duty to protect the patient's privacy shall be upheld and requirements regarding medical records and issuance of various certificates shall be fully understood. Such records shall be maintained with integrity and accuracy.

6. Doctors shall respond appropriately so that the patient's quality of life does not deteriorate because of pain and suffering during medical care.

7. Doctors shall respect patients and maintain a patient-doctor relationship based on mutual trust.

8. Doctors shall communicate actively with patients, their guardians, and other medical professionals.

9. Doctors shall acknowledge the limits of modern medicine and exert an open-minded effort to overcome such limits.

10. Upon encountering a patient with a condition beyond one's knowledge or experience, doctors shall seek the assistance of other appropriate medical professionals and cooperate when asked for advice or the referral of patients.

11. Doctors shall comply with professional ethics and develop their medical expertise to acquire the best aptitude and professional attitude for patient care.

12. Doctors shall pursue extensive measures for the safety of their patients.

13. In an emergency, doctors shall perform prompt care and transfer the patient to a medical institution capable of follow-up care if necessary to prevent the situation from worsening.

14. Doctors shall educate patients about drug interactions and possible adverse effects of drugs, and shall exert efforts to prevent drug addiction and abuse.

15. In a situation involving the safety of the patient, doctors shall place the highest priority on patient protection and shall take appropriate follow-up measures.

\section{[Domain 2: communication and collaboration]}

16. Doctors shall understand and empathize with their patients; further, they shall be able to appropriately express their appreciation regarding each patient's position.

17. Doctors shall listen to patients with care and respect their opinions.

18. Doctors shall protect each patient's privacy and personal values.

19. Doctors shall pursue a patient-doctor relationship based on honesty and trust.

20. In a situation posing harm to the patient, doctors shall take appropriate measures and resolve problems through communication and cooperation.

21. When termination of care, consultation, referral, or a transfer to another hospital is necessary, doctors shall explain such reasons sufficiently to the patient and guardian in advance.

22. When the patient has difficulties cooperating and communicating because of special circumstances, doctors shall request professional assistance if necessary.

23. Doctors may provide sufficient information to patientso guardians and seek their cooperation while respecting patient privacy if such efforts are beneficial to patient care.

24. Doctors shall understand and respect the positions of patientso family members or guardians.

25. Doctors shall closely communicate and cooperate with all colleagues, including medical and non-medical personnel.

26. Doctors shall respect the abilities, experience, and opinions of each member of the medical team and follow clearly defined roles and responsibilities.

27. When referring patients or delegating patient care to colleagues, doctors shall provide appropriate and sufficient information.

28. Doctors shall not engage in groundless criticism of other doctors (colleagues).

29. Doctors shall actively participate in training that may enhance their understanding of other professions.

30. When necessary for effective care and better public health, doctors shall communicate and cooperate with numerous related organizations.

31. Doctors shall provide truthful information beneficial to the public good when providing information related to the public health.

32. Doctors shall identify various factors that influence the health of individuals, the community, and the nation, and shall be able to appropriately respond to such factors. 


\section{[Domain 3: social accountability]}

33. Doctors shall meet patients' demands for better personal health during patient care.

34. Doctors shall identify factors and needs that influence the health of local residents and take appropriate action.

35. Doctors shall provide professional insight on information and solutions regarding the promotion of health in the community.

36. Doctors shall actively cooperate with activities to promote health within the local community and country, such as the control of contagious diseases.

37. Doctors shall identify the health issues of the medically disadvantaged and shall exert efforts to resolve them.

38. Doctors shall understand the social, economic, cultural, and ethical implications of medicine-related laws and systems and actively respond to shifts in the medical field.

39. Considering limited medical resources, doctors shall maintain fairness and increase the efficiency of medical institutions and public health systems.

40. Doctors shall be capable of performing as managers and leaders in the public health system.

41. Doctors shall cooperate in health protection activities in the event of a domestic disaster.

42. Doctors shall understand the meaning of international disaster relief activities and participate in such activities.

43. Doctors shall support the public health activities of international organizations and participate in international exchanges.

\section{[Domain 4: professionalism]}

44. Doctors shall assess their own medical capabilities honestly and shall not promote them in an exaggerated manner.

45. Doctors shall maintain their capabilities to provide the best patient care based on their consciences and clinical autonomy.

46. Doctors shall be aware of the duty to protect patient privacy and shall abide by such principles.

47. Doctors shall provide medical information through due process for a justified cause.

48. Doctors shall be capable of maintaining the patient-doctor relationship within a professional context.

49. Doctors shall be capable of managing conflict of interest situations that occur in the course of patient care.

50. Doctors shall respect the political, social, and religious beliefs of patients in the course of care and shall not discriminate or demonstrate prejudice based on patientsb beliefs. Additionally, the doctor shall not forcefully impose his/her own belief system on patients.

51. Doctors shall fully understand and comply with the ethical guidelines required by law and the medical profession.

52. Doctors shall faithfully perform the duties demanded by professional organizations and related bodies.

53. Doctors shall take appropriate action when a colleague damages their profession.

54. Doctors shall actively participate in various self-regulation activities.

55. Doctors shall maintain an appropriate balance between their work and personal lives.

56. Doctors shall maintain an appropriate level of personal health.

57. Doctors shall be capable of systematically responding to protect their work in the healthcare environment.

58. Doctors shall request the assistance of other colleagues in matters related to their own health and shall actively cooperate when asked for help by other doctors.

\section{[Domain 5: education and research]}

59. Doctors shall maintain and promote professional capabilities through lifelong learning.

60. Doctors shall be capable of performing the role of educator toward patients, guardians, medical professionals, and the general public.

61. Doctors shall be capable of conducting fair peer assessments based on scientific evidence.

62. Doctors shall understand scientific principles and methods of medical research.

63. Doctors shall select and apply scientific methods to respond to questions that arise during patient care.

64. Doctors shall be able to appropriately analyze and utilize the results of medical research.

65. Doctors shall comply with relevant ethical principles and guidelines when conducting medical research involving human subjects. 